\title{
Multivariate Analysis of Genetic Divergence and Character Association in Ethiopian Kale Accession (Brassica Carinata A)
}

\author{
Asfaw Yenenesh Wudneh \\ Ethiopian Institute of Agricultural Research (EIAR), \\ Debre-zeit Agricultural Research Center (DZARC), \\ P.O.Box 32. Debre-zeit, Ethiopia
}

\begin{abstract}
Ethiopian kale is an important crop of Ethiopian origin and it has been grown in Ethiopia since antiquity both as a vegetable and oilseed crop. Cultivation of Ethiopian kale, as a vegetable, requires genetic improvement which relies on its genetic diversity and interrelationships among traits. The objective of this research is to the study and analyse the Ethiopian kale accession association among yield and yield related traits of genetic divergence and character association. The experiment was carried out using $7 x 7$ simple lattice design at Debre-zeit agricultural research center. In this study, genetic diversity in 49 Ethiopian kale accessions, collected from the diverse agro-ecological area of the country were assessed using the techniques of cluster and principal component analyses based on 14 traits. Multivariate analyses of genetic divergence among accessions have resulted in the formation of three clusters, and have shown the presence variability for further selection and breeding. The largest and smallest numbers of accessions were found under cluster one and three respectively. The accessions subjected to divergence study fall in to different cluster showing the existence of significant difference $(p<0.01)$ between all pairs of clusters. The maximum inter-cluster distance was found between cluster one and three which are better to use as a parent, while the minimum distance was showed between two and one. $75.8 \%$ of the variation was contributed by the fourth principal components among the accessions using agro-morphological traits. PC1 had 33.94\% of total variation in agro morphological traits; PC2 depicted $21.45 \%$ of total morphological variability, while PC3 and PC4 accounted for $12.11 \%$ and 8.3 respectively, for the total variation.
\end{abstract}

Key words: Cluster, Genetic Divergence, Principal Component Analysis, Selection, Variation.

\section{INTRODUCTION}

Ethiopian kale (Brassica carinata A. Braun) belongs to the family Brassicaceae. It originated through interspecific hybridization between Brassica nigra and Brassica oleracea followed by chromosome doubling, in the highlands of Ethiopia and adjoining regions of East African and Mediterranean coast [1,2]. It is an annual or occasionally biennial or perennial and self-pollinated with about $30-50 \%$ outcrossing [3]. The plant grows and can be harvested all year round. Flowering is delayed by regular harvesting of leaves and young shoots [4].

Recently it has been cultivated in different parts of the world including Central Africa (Zambia), West Africa (Sierra Leon and Guinea) and Asia (India) as a vegetable crop along with other members of the genus. This crop is also extensively cultivated in Eastern Europe and U.S.A [5]. The culture and cultivation of Ethiopian kale in Ethiopia is as old as cultivation of cereals, which is believed to date back in the $4^{\text {th }}$ to $5^{\text {th }}$ Millennia B.C. [6]. The area under kale is unlikely to be extended further due to the planting of other competitive crops. The crop is often grown as a backyard crop on humus-rich soils by small holder farmers following traditional practices [7].

Ethiopian kale is commonly used as a vegetable in Ethiopia [8]. The young leaves and branches are usually used as a side dish after it has been cooked and served with the known local food of Ethiopia, 'Enjera' [9]. It is important as they are a key components of the local diet and nutritionally very important for people who cannot afford alternative vegetables [10]. For everyday meal as a vegetable it is advantageous because; it has special nutritional components like vitamins, minerals, trace 
elements, dietary fiber and protein. It also gives test and flavor of diets [9, 11]. Since the time of our forefathers, it has saved the lives of many Ethiopians. Moreover, its adaptation in semi-arid environment makes it an ideal candidate in a country like Ethiopia, despite of the fact that it has important nutritional qualities [9]. In addition to the general use of the crop apart of meal, it also serves the purpose of being used for oil extraction along with other oilseed crops [12].

Ethiopian kale produced the greatest number of leaves and in height clearly exceeded both parental species and others [13]. In the case of stem biomass, B. carinata was much larger than any other Brassica species. Despite its long history and deep-rooted tradition of production in Ethiopia, however, until very recently it has never been known as a full-fledged field crop. This might be due to the fact that the crop has been widely neglected by research and development programs [14]. There is no direct attention paid to these species. Crop research in Ethiopia has largely concentrated on cereal, oil and industrial crops. Hence, to augment kale production, the only recourse is to boost up productivity. Farmers have shown interest in the crop, but this attraction could be further enhanced by developing varieties with better agronomic qualities [15].

But, to take advantage of these important traits, the diversity should be studied. In addition to that, the regions with high diversity as well as those endowed with useful agronomic traits needs to be identified for further core collection of the plant [16]. Analysis of genetic relationships in crop species is an important component of crop improvement. It helps to analyze genetic variability of cultivars [17], select parental materials for hybridization for making new gene recombination, select inbred parents or testers for maximizing heterotic response and identify materials that should be maintained to preserve maximum genetic diversity in germplasm Sources [18].

In future studies, knowledge obtained from clustering of populations of B. carinata in the present study could be used as a benchmark for future collection and characterization of landraces. Therefore, this experiment was undertaken to determine the genetic relationships among the accessions collections of Ethiopian kale (B. carinata) based on multivariate analyses of yield and yield related traits.

\section{MATERIALS AND METHODS}

\subsection{Experimental Site}

The field experiment was conducted at DebreZeit Agricultural Research Center (DZARC) during the 2018 main cropping season. DZARC is located at $47 \mathrm{Km}$ East of Addis Ababa, in East Showa Zone Ada district, $08^{0} 44^{\prime} \mathrm{N}$ latitude and $38^{0} 58^{\prime}$ E longitude at an altitude of 1860 masl. The area has two growing seasons, main season which is rain fed and off-season which is irrigation based. The area has minimum and maximum temperature of 19.03 and $26.91{ }^{\circ} \mathrm{C}$ respectively, annually and it receives average annual rainfall of $851 \mathrm{~mm}$. The soil type of the center is classified as black soil (Vertisol) and light soil.

\subsection{Experimental Design and Treatments}

A total of forty nine Ethiopian kale accessions including one local check were used for the study. The accessions were collected from SNNPR and Oromia region by DZARC from diverse agro-ecological area (Table 1). The study was carried out in a 7x7 simple lattice design and seven accessions were assigned into each incomplete block, using $2 \mathrm{~m}$ long $\mathrm{x} 2 \mathrm{~m}$ wide plot. The spacing between replications, incomplete blocks and plots were $2 \mathrm{~m}, 1 \mathrm{~m}$ and $50 \mathrm{~cm}$, respectively. Spacing between rows and plants were 50 $\mathrm{cm}$ and $30 \mathrm{~cm}$, respectively. Irrigation was supplied based on crop requirement and soil condition. The field management like fertilizer, weed control were maintained and plant protection measures were done.

\subsection{Data collected}

Data were collected on fourteen traits on plot basis, and from randomly taken five plants from the two central rows of each plot based on descriptors of Brassica and Raphanus [19] viz., Plant height (PH), Plant Canopy Width (PCW), Leaf fresh weight (LFW), Leaf dry matter content(DM), Fresh biomass (BM), Number of leaves per plant (NLP), Leaf length (LL), Leaf width (LW), Leaf Petiole length (LPL), Leaf petiole thickness (LPT), Leaf area (LA), Days to first leaf picking (DFLP), Days to second leaf picking (DSLP) and Leaf yield per hectare (LY).

\subsection{Statistical Analysis}

Multivariate analysis: Genetic divergence analysis was computed based on multivariate analysis using Mahalanobis's $\mathrm{D}^{2}$ statistic [20]. 
Clustering analysis: The analysis was estimated using SAS software version 9.3 [21], so as to group sets of genotype in to homogenous clusters. Genetic distances between clusters as standardized by Mahalanobis's $\mathrm{D}^{2}$ statistics was calculated as:

$\mathrm{D}_{\mathrm{ij}}^{2}=\left(\mathrm{x}_{\mathrm{i}}-\mathrm{x}_{\mathrm{j}}\right) \operatorname{cov}^{-1}\left(\mathrm{x}_{\mathrm{i}}-\mathrm{x}_{\mathrm{j}}\right)$

Where, $\mathrm{D}_{\mathrm{ij}}^{2}=$ the squared distance between two genotypes $\mathrm{i}$ and $\mathrm{j}$;

$x_{i}$ and $x_{j}=$ vectors of the values of the variables for the genotype $i$ and $j$ and

$\operatorname{cov}^{-1}=$ the pooled within groups variance-covariance matrix.

The $\mathrm{D}^{2}$ values obtained for pairs of clusters was considered as the calculated values of Chi square $\left(\mathrm{X}^{2}\right)$ and clustering of genotypes were done using Average Linkage Cluster Analysis method as described by [22].

Estimation of intra and inter cluster squared distance: Average Intra and Inter cluster distance was obtained by the formula $\frac{\sum \mathrm{Dij}^{2}}{\mathrm{n}}$, where $\sum \mathrm{Dij}^{2}$ is the sum of distance between all possible combinations (n) of the genotypes included in a cluster. The correlation matrix is used to calculate the intra and inter cluster squared distances. Significance of the squared distances for each cluster was tested against the tabulated $\chi^{2}$ values at $\mathrm{p}$ degree of freedom at $1 \%$ and $5 \%$ probability level, where $\mathrm{p}=$ number of traits used for clustering genotypes.

Principal component analysis: Principal component analysis (PCA) was used to find out the traits, which accounted more to the total variation. Principal components based on correlation matrix were calculated using SAS software.

Table 1. Ethiopian kale accessions used for the variability studies

\begin{tabular}{|c|c|c|c|c|c|}
\hline No & $\begin{array}{c}\text { Sample/ Coll. } \\
\text { Number }\end{array}$ & Accessions & No & $\begin{array}{r}\text { Sample/ Coll. } \\
\text { Number }\end{array}$ & Accessions \\
\hline 1 & EK-002 & Landrace & 26 & EK-046 & Landrace \\
\hline 2 & EK-003 & Landrace & 27 & EK-047 & Landrace \\
\hline 3 & EK-004 & Landrace & 28 & EK-048 & Landrace \\
\hline 4 & EK-005 & Landrace & 29 & EK-051 & Landrace \\
\hline 5 & EK-006 & Landrace & 30 & EK-052 & Landrace \\
\hline 6 & EK-007 & Landrace & 31 & EK-053 & Landrace \\
\hline 7 & EK-012 & Landrace & 32 & EK-054 & Landrace \\
\hline 8 & EK-018 & Landrace & 33 & EK-056 & Landrace \\
\hline 9 & EK-020 & Landrace & 34 & EK-057 & Landrace \\
\hline 10 & EK-021 & Landrace & 35 & EK-058 & Landrace \\
\hline 11 & EK-022 & Landrace & 36 & EK-059 & Landrace \\
\hline 12 & EK-024 & Landrace & 37 & EK-060 & Landrace \\
\hline 13 & EK-027 & Landrace & 38 & EK-061 & Landrace \\
\hline 14 & EK-028 & Landrace & 39 & EK-062 & Landrace \\
\hline 15 & EK-033 & Landrace & 40 & EK-063 & Landrace \\
\hline 16 & EK-034 & Landrace & 41 & EK-064 & Landrace \\
\hline 17 & EK-035 & Landrace & 42 & EK-066 & Landrace \\
\hline 18 & EK-036 & Landrace & 43 & EK-067 & Landrace \\
\hline 19 & EK-038 & Landrace & 44 & EK-069 & Landrace \\
\hline 20 & EK-039 & Landrace & 45 & EK-070 & Landrace \\
\hline 21 & EK-040 & Landrace & 46 & EK-074 & Landrace \\
\hline 22 & EK-041 & Landrace & 47 & EK-075 & Landrace \\
\hline 23 & EK-042 & Landrace & 48 & EK-076 & Landrace \\
\hline 24 & EK-043 & Landrace & 49 & EK-081 & Local check \\
\hline 25 & EK-044 & Landrace & & & \\
\hline
\end{tabular}

Source: Debre Zeit Agricultural Research Center (DZARC) 


\section{RESULTS AND DISCUSSION}

\subsection{Multivariate Analysis}

\subsubsection{Clustering of Accessions}

Clustering based on the traits produced a clear grouping of 49 accessions in to three clusters, (Figure 1) whereby the individuals within any one cluster are more closely related than individuals in different cluster. The accessions were grouped in such a way that cluster I had the largest member of all cluster, include $24(48.98 \%)$ accessions followed by $22(44.9 \%)$ in $\mathrm{C} 2$ and $3(6.12 \%)$ in C3. In the present study, accession gained from different source center clustered in the same category together, for instance, in cluster I accessions collected from Gurage, Sidama, Gedeo and East showa grouped together (Table 2). The possible reason could be common ancestor of these accessions, due to free exchange of accessions among the breeders of different regions. Moreover, accessions collected from the same source of center were clustered in to different clusters, suggesting the existence of genetic diversity within each collection source. The grouping of accessions indicated that geographical distribution need not necessarily be the indicator of genetic divergence.

Table 2. Cluster of 49 Ethiopian kale accessions evaluated in 2017/18 main cropping season at DZARC

\begin{tabular}{|c|c|c|c|}
\hline Cluster & No. of Acc. & Accessions & Proportion (\%) \\
\hline $\mathrm{C} 1$ & 24 & $\begin{array}{l}\text { EK-69,Ek-58, Ek-51, Ek-18, Ek-66, Ek-74, Ek-64, Ek-81, } \\
\text { Ek-75, Ek-48, Ek-46, Ek-62, Ek-76, Ek-56, Ek-57, Ek-20, } \\
\text { Ek-41, Ek-63, Ek-44, Ek-39, Ek-47, Ek-70, Ek-59, Ek-60 }\end{array}$ & 48.98 \\
\hline $\mathrm{C} 2$ & 22 & $\begin{array}{l}\text { EK-7, EK-40, EK-28,Ek-61,Ek-52,Ek-38,Ek-43, } \\
\text { Ek-21,Ek-33,Ek-35,Ek-67,Ek-54,Ek-12,Ek-42, } \\
\text { Ek-36,Ek-2,Ek-34,Ek-4,Ek-53,Ek-6,Ek-27,Ek-5 }\end{array}$ & 44.90 \\
\hline C3 & 3 & Ek-24,Ek-3,Ek-22 & 6.12 \\
\hline
\end{tabular}

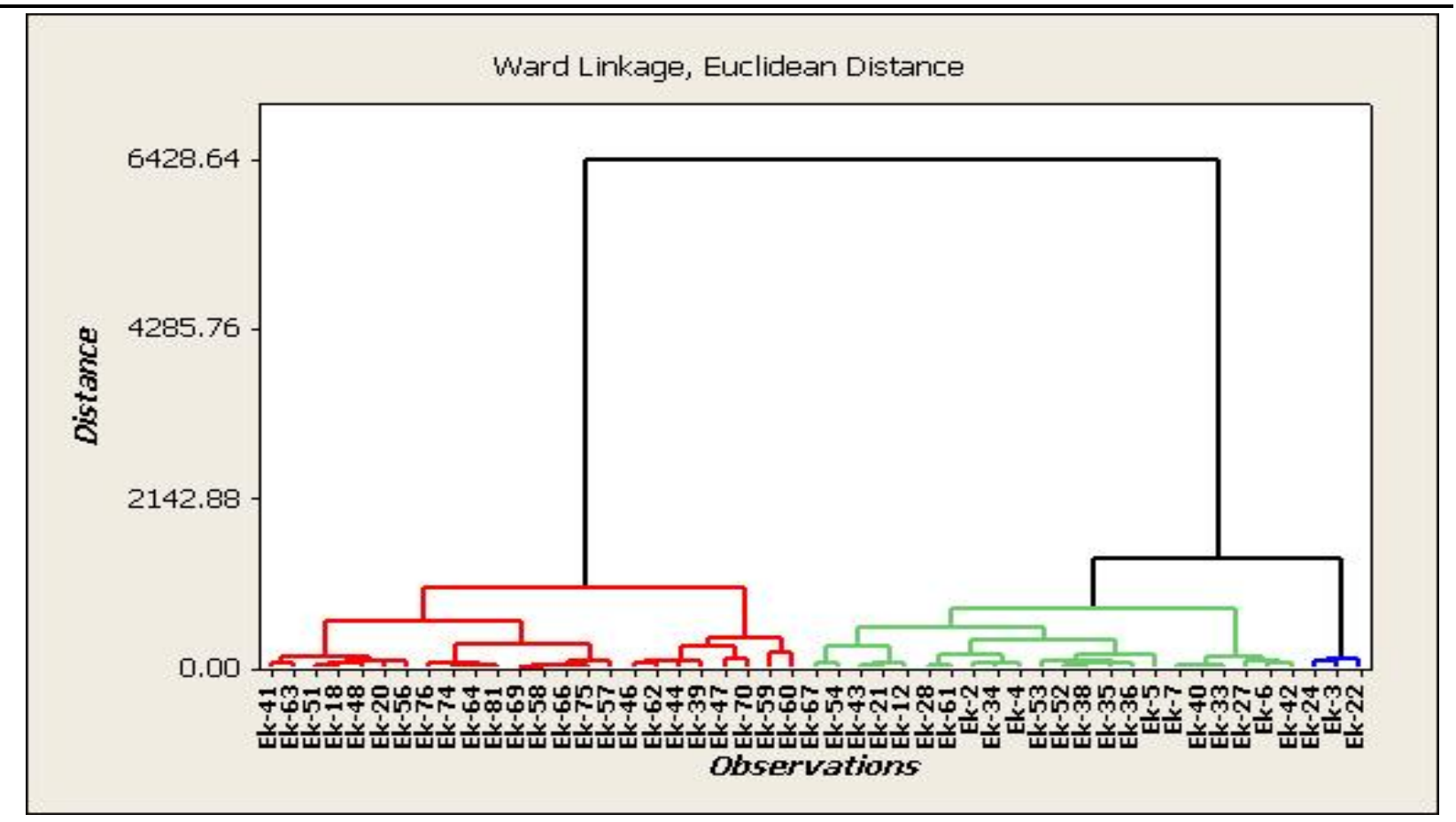

Figure 1. Dendrogram showing relationship among 49 Ethiopian kale accessions using the mean of 14 characters.

\subsubsection{Comparison of Accession Performances among Clusters}

The results of cluster analysis for 14 studied traits in 49 accessions are presented in Table 3 . All the accessions were classified in three groups with different mean values of the traits. Cluster I was characterized by the lowest cluster mean estimate for days to first leaf picking, days to second leaf picking, low in number of leaves per plant, leaf weight per plant, leaf dry matter content and 
leaf yield; and the highest cluster mean value for leaf fresh weight and leaf petiole thickness. Cluster II had a characteristic feature of low value in terms of plant height, leaf width, leaf petiole thickness, biomass and leaf area on the other hand had high value in terms of days to second leaf picking as compared to the other. Cluster III showed high value in terms of leaf weight per plant, leaf dry matter content, leaf length, leaf area, biomass and leaf yield and the lowest cluster mean value for leaf petiole thickness. The 49 genotypes of oil seed Ethiopian kale that were collected from 12 different Ethiopian agro ecological zones of the country were grouped in to four clusters [23]. [24] Studied seventeen genotypes of Amaranthus. The genotypes were grouped in to four clusters regardless of their origin.

Table 3. Cluster mean value of three clusters for 14 characters of 49 Ethiopian kale accessions evaluated in $2017 / 18$ main cropping season at DZARC

\begin{tabular}{|c|c|c|c|}
\hline Traits & Cluster mean & & \\
\hline & $\mathrm{C} 1+\mathrm{SD}$ & $\mathrm{C} 2 \pm \mathrm{SD}$ & $\mathrm{C} 3 \pm+\mathrm{SD}$ \\
\hline $\mathrm{PH}$ & $68.84 \pm 12.44$ & $62.87 \pm 5.44$ & $69.04 \pm 4.81$ \\
\hline PCW & $57.44 \pm 7.58$ & $59.64 \pm 6.26$ & $63.86 \pm 1.52$ \\
\hline NLP & $44.87 \pm 16.00$ & $73.19 \pm 32.91$ & $76.09 \pm 12.42$ \\
\hline LWT & $412.00 \pm 87.77$ & $777.96 \pm 82.64$ & $1126.30 \pm 46.20$ \\
\hline $\mathrm{DM}$ & $63.07 \pm 19.30$ & $111.70 \pm 20.45$ & $139.07 \pm 8.58$ \\
\hline LL & $22.52 \pm 2.33$ & $22.65 \pm 2.77$ & $33.83 \pm 10.83$ \\
\hline LW & $17.19 \pm 4.07$ & $13.81 \pm 1.64$ & $15.30 \pm 0.51$ \\
\hline LPL & $6.87 \pm 1.35$ & $7.98 \pm 0.84$ & $8.61 \pm 0.83$ \\
\hline LPTH & $12.57 \pm 3.09$ & $9.87 \pm 1.81$ & $12.23 \pm 0.78$ \\
\hline LA & $244.85 \pm 68.94$ & $220.19 \pm 47.80$ & $265.12+26.42$ \\
\hline DFLP & $49.06 \pm 4.45$ & $54.27 \pm 3.46$ & $57.00+1.00$ \\
\hline DSLP & $80.67 \pm 6.00$ & $87.59 \pm 19.61$ & $86.33 \pm 0.47$ \\
\hline $\mathrm{BM}$ & $0.27 \pm 0.14$ & $0.22 \pm 0.08$ & $0.34 \pm 0.09$ \\
\hline LY & $15.11 \pm 4.74$ & $24.66 \pm 4.21$ & $26.82 \pm 6.28$ \\
\hline
\end{tabular}

Where, PH=plant height, PCW=plant canopy width, NLP= number of leaf per plant, LWT=leaf fresh weight per plant, DM= leaf dry matter content, $\mathrm{LL}=$ leaf length, $\mathrm{LW}=$ leaf width, $\mathrm{LPL}=$ leaf petiole length, $\mathrm{LPTH}=$ leaf petiole thickness, $\mathrm{LA}=$ leaf area, $\mathrm{DFLP}=$ days to first leaf picking, DSLP=days to second leaf picking, $\mathrm{BM}=$ biomass, $\mathrm{LY}=$ leaf yield per hectare

\subsubsection{Distance among clusters (genetic divergence analysis)}

The pair wise generalized squared distance $\left(\mathrm{D}^{2}\right)$ between and within clusters are presented in Table 4 . The standardized Mahalanobis $\mathrm{D}^{2}$ stastics showed highly significant difference between all clusters, and the genetic divergence between all pairs were highly significant $(\mathrm{p} \leq 0.01)$. Regarding the inter cluster distance, the highest genetic distance was recorded between $\mathrm{CI}$ and CIII $\left(D^{2}=147.84\right)$ followed by the cluster CIII and CI $\left(D^{2}=143.68\right)$, indicating wider genetic divergence among clusters. The higher inter cluster distance values in this study might be larger due to the inclusion of accessions which have wider genetic diversity. The extent of diversity present in the studied accessions implied the opportunity of Ethiopian kale improvement through hybridization followed by selection. The maximum inters cluster distance, the large magnitude of genetic variability among accessions and thus the better probability to create wider genetic bases through hybridization. The more diversity of parents the greater chance of obtaining high heterosis [25]. In this study, a cross which involves accessions from cluster one and three might be rewarding for the improvement of Ethiopian kale through heterosis breeding and will help to develop superior inbred lines.

Higher inter cluster distance was obtained from CIII (5.59) followed by CII (1.60) and CI (1.43). Genetic divergence study reported by earlier worker showed high diversity among genotypes [26, 27]. The minimum distance was obtained between CII and CI $\left(D^{2}=40.38\right)$ followed by the genetic distance CI and CII with $\left(D^{2}=40.56\right)$ indicating that accessions of these two clusters were relatively less diverse. Thus, crossing of accessions from these two clusters will produce progenies with less amount of hetrotic expression in the F1's and narrow range of variability in the subsequent segregation (F2) population. 
International Journal of Advances in Scientific Research and Engineering (ijasre), Vol 6 (10), October -2020

Table 4. Inter and intra (bold) cluster $D^{2}$ values among three clusters in 49 Ethiopian kale accessions evaluated in $2017 / 18$ main cropping season at DZARC

\begin{tabular}{llll}
\hline Cluster & I & II & III \\
\hline I & $\mathbf{1 . 4 3}$ & $40.56^{* * *}$ & $147.84^{* * *}$ \\
II & $40.38^{* *}$ & $\mathbf{1 . 6 0}$ & $47.82^{* *}$ \\
III & $143.68^{* *}$ & $43.84^{* *}$ & $\mathbf{5 . 5 9}$ \\
\hline
\end{tabular}

$* *=$ significant, $\mathrm{X}^{2}=27.69$ and 22.36 at $1 \%$ and $5 \%$ probability level, respectively.

\subsubsection{Principal component analyses}

In order to assess the patterns of variation, principal component analysis (PCA) scores might be used to summarize the original 14 traits simultaneously for further analysis of the data (Table 5). The first four Principal components which have eigen value greater than one accounted $75.8 \%$ of the total variation among Ethiopian kale accessions for fourteen traits.

Table 5. Eigenvectors, eigenvalues and percentage of total variance explained by the first four principal components (PC) for 14 traits in 49 Ethiopian kale accessions evaluated in 2017/18 main cropping season at DZARC

\begin{tabular}{lllll}
\hline & PCA 1 & PCA 2 & PCA 3 & PCA 4 \\
\hline PH & -0.07 & -0.05 & 0.39 & 0.66 \\
PCW & 0.12 & 0.15 & -0.57 & 0.36 \\
NLP & 0.31 & -0.09 & 0.32 & 0.28 \\
LWT & 0.31 & 0.38 & 0.00 & 0.07 \\
DM & 0.37 & 0.24 & 0.12 & 0.07 \\
LL & -0.03 & 0.38 & -0.31 & 0.18 \\
LW & -0.40 & 0.22 & 0.08 & -0.03 \\
LPL & 0.30 & 0.08 & -0.32 & 0.18 \\
LPTH & -0.37 & 0.24 & -0.09 & 0.00 \\
LA & -0.31 & 0.35 & -0.01 & -0.02 \\
DFLP & 0.13 & 0.41 & 0.26 & -0.29 \\
DSLP & 0.05 & 0.19 & 0.28 & 0.09 \\
BM & -0.25 & 0.30 & 0.18 & 0.30 \\
LY & 0.29 & 0.29 & 0.12 & -0.32 \\
Eigenvalue & 4.75 & 3.00 & 1.69 & 1.16 \\
Difference & 1.75 & 1.31 & 0.53 & 0.20 \\
Total variance explained $(\%)$ & 33.94 & 21.45 & 12.11 & 8.30 \\
Cumulative total variance explained $(\%)$ & 33.94 & 55.40 & 67.51 & 75.80 \\
\hline
\end{tabular}

Where, $\mathrm{PH}=$ plant height, $\mathrm{PCW}=$ plant canopy width, NLP= number of leaves per plant, LWT=leaf fresh weight per plant, DM= leaf dry matter content, $\mathrm{LL}=$ leaf length, $\mathrm{LW}=$ leaf width, $\mathrm{LPL}=$ leaf petiole length, $\mathrm{LPTH}=\mathrm{leaf}$ petiole thickness, $\mathrm{LA}=\mathrm{leaf}$ area, $\mathrm{DFLP}=$ days to first leaf picking, DSLP=days to second leaf picking, $\mathrm{BM}=$ biomass, $\mathrm{LY}=$ leaf yield per hectare

The first principal component had high positive loading for eight characters out of fourteen (Figure 2). Number of leaves per plant, leaf fresh weight per plant, leaf dry matter content and leaf petiole length which contributed more to the variation. It has high negative weights for leaf width, leaf petiole thickness and leaf area. Additional $21.45 \%$ variation in the second principal component was mainly observed in leaf fresh weight per plant, leaf length, leaf area, days to first leaf picking and biomass. The third principal component accounted for another additional $12.11 \%$ of the variation in which plant height and number of leaves per plant are the major positive contributors. Plant canopy width, leaf length and leaf petiole length expressed highest negative loads in principal component three $\left(\mathrm{PCA}_{3}\right)$. 


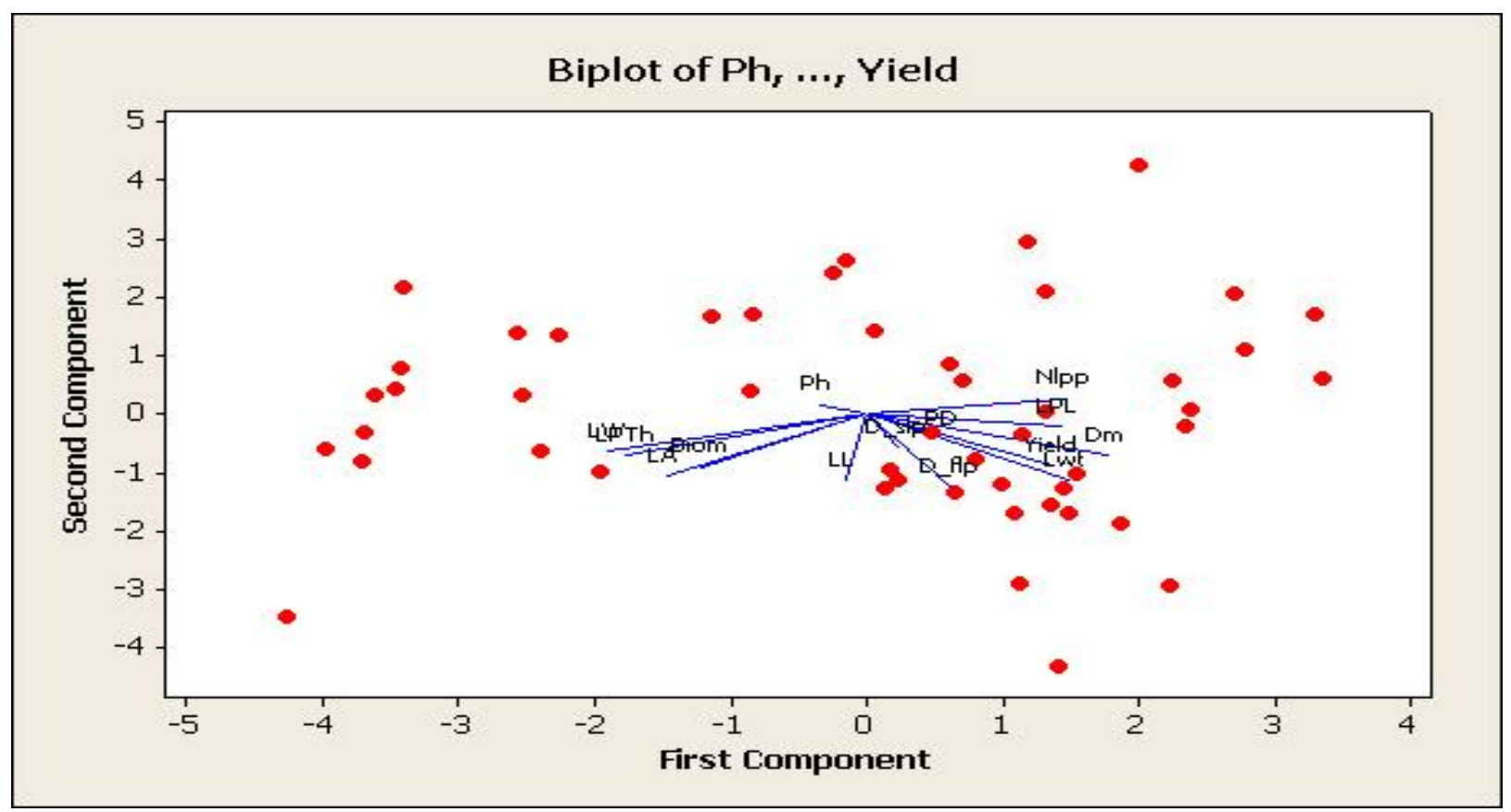

Figure 2. Plot of the first two PCAs showing the contribution of various traits to total variation

The major contributing traits for the variation in the four principal components $\left(\mathrm{PC}_{2}\right)$ were chiefly obtained from variations of plant height, plant canopy width and biomass. It has high negative weights for leaf yield. The positive and negative weight shows the presence of positive and negative correlation trends between the components and the variables. Therefore, the above mentioned characters with high positive or negative loads contributed more to the diversity and they were the ones that most differentiated the clusters.

In general, it is assumed that traits with larger absolute values closer to unity with in the first principal component influence the clustering more than those with lower absolute values closer to zero [28]. In this study, most of the traits individually contributed small effects $( \pm 0.03-0.37)$ to the total variation. Plant canopy width had the highest negative weight. Principal of accessions was mainly attributed by the cumulative effect of the individual trait. [29] Carried out PCA based on twenty quantitative morphological characters. The seven principal components accounted for $73.92 \%$ of the overall variability among the studied Indian mustard accessions for the total phenotypic variations. According to [30] PCA explained over $77 \%$ of the total variation for 27 quantitative and qualitative agro-morphological characters in Swiss chard.

\section{SUMMARY AND CONCLUSION}

Cluster and distance analysis of quantitative characters based on multivariate analysis pointed out the existence of three divergent groups. The inter cluster distance was maximum between cluster one and three $\left(D^{2}=147.84\right)$, while the minimum distance was between two and one $\left(D^{2}=40.56\right)$. Path coefficient analysis of leaf yield contributing attributes revealed that number of leaf per plant, leaf fresh weight, leaf dry matter and days to first leaf picking which indicated that these are the main contributors to the green foliage yield. Hence these components should be considered while making selection strategies for the improvement of yield for Ethiopian kale.

\section{REFERENCE}

[1]. Simmonds, N.W. 1979. Longman Principles of Crop Improvement Group, New York.

[2]. Choung P.V. Bevedrof W.D. 1985. High frequency embryogenesis through isolated microspore culture in B. napus and B. carinata. Plant Science. 39: 219-226.

[3]. Rakow G. 2004. Species origin and economic importance of Brassica. Biotechnology in Agriculture and Forestry. 54: 3-7.

[4]. Mnzava N and Schippers R 2004. Brassica carinata A Braun [Internet] Record from Protabase.

[5]. Mnzava, N. and Schippers, R., 2007. Brassica carinata A. Braun In: van der Vossen, H.A.M. \&Mkamilo, G.S. Ed. PROTA 14: Vegetable oils/Oléagineux. [CD-Rom].PROTA, Wageningen, Netherlands.

[6]. Alemayehu, N., Becker, H. and Gebeyehu, G., 1999, September. Genetic variabilities in Ethiopian mustard (Brassica carinata Braun) for quality characteristics. In Proceding of the 10th International Rapeseed Conference pp. 26-29. 
[7]. Alemayehu, N., Adefris, T. and Zerihun, T., 1996. Effect of agronomic practices on seed and oil yields of Ethiopian mustard (Brassica carinata A. Braun.) and rape seed (B. napus L.). Tropical agriculture, 73(2), pp.94-99.

[8]. Alemayehu, N. and Becker, H.C., 2001. Variation and inheritance of erucic acid content in Brassica carinata germplasm collections from Ethiopia. Plant breeding, 120(4): 331-335.

[9]. Asfaw, Z., 1997. Conservation and use of traditional vegetables in Ethiopia. In Traditional African Vegetables: Proceedings of the IPGRI International Workshop on Genetic Resources of Traditional Vegetables in Africa. Conservation and Use. ICRAF-HQ, Nairobi. Institute of Plant Genetic and Crop Plant Research, Rome pp. 57-65.

[10]. Oruku L. and Ndun'gu B.2001. Final socio-economic report for the peri-urban vegetable Reregistration Eligibility Decision (RED) Capsaicin, Case 4018; U.S.

[11]. Genet, T., Labuschagne, M. and Hugo, A., 2005. Genetic relationships among Ethiopian mustard genotypes based on oil content and fatty acid composition. African Journal of Biotechnology, 4(11): 1256-1268.

[12]. Alemayehu, A., 2001. Germplasm diversity and genetics of quality and agronomic traits in Ethiopian mustard (Brassica carinata A. Braun.CuvillierVerlag.

[13]. Courtny J., Murren and Massimo P. 2005. Morphological response to simulated wind in the genus Brassicaseae: allopolyploids and their parental species. Amer. J. Bot. 92: 810-818.

[14]. Jianchu X., Yang Y., Yingdong PW., Ayad G. and Eyzagủirre PB. 2001. The genetic diversity in taro (Colocasia esculenta Schott-Araceae) in China: An Ethno botanical and genetic approach Economic Botany. 55(1): 14-31.

[15]. Teklewold, A., 2005. Diversity study based on quality traits, RAPD Markers, and Investigation of Hetrosis in Ethiopian Mustard. PhD. Thesis presented to George-Augest University of Gottingen, Germany, 160p.

[16]. Ahmed, H., Hasnain, S., and Khan, A. 2002. Evolution of genomes and genome relationships among the rapeseed and mustard. Biotechn. 1: 78-87.

[17]. Singh, B.D. 1983. Methods. Plant Breeding Principles and Kalyani Publisher, New Delhi, India.

[18]. Thormann, C.E. and Osborn, T.C. 1992. Use of RAPD and RFLP markers for germplasm evaluation. In: Application of RAPD technology to plant breeding (Joint Plant Breeding Symposia Series, Nov 92). Crop Science Society of America. pp. 9-11.

[19]. IBPGR, 1990. Descriptors for Brassica and Raphanus. International board for plant genetic resources, Rome.

[20]. Mahalanobis, P., 1936. The Generalized Distance in Statistics. Proceedings of the National Institute of Sciences of India, 49-55.

[21]. SAS (Stastical Analysis System) Software, 2009. Version 9.3. Inc. Cary, North California USA.

[22]. Singh, R., and Chaudhary B. 1977. Biometerical methods in quantitative genetic analysis. Kalayani Publishers, New DelhiLudhiana, India.

[23]. Belete Y., 2011. Genetic Variability, Correlation and Path Analysis Studies in Ethiopia Mustard (Brassica Carinata A.) Genotypes. International Journal of Plant Breeding and Genetics, 5: 328-338.

[24]. Akther, C., Hasan, M., Raihan, M., Hossain, M. and Mian M., 2013. Genetic Divergence in Stem Amaranth (Amaranthus tricolor L.) Genotypes for Yield and its Component Characters. The Agriculturists, 11(1): 82-88.

[25]. Zaman MR, Paul DNR, Kabir MS, Mahbub MAA, Bhuiya MAA 2005. Assessment of Character Contribution to the Divergence for some Rice Varieties. Asian J. Plant Sci. 4(4):388-391.

[26]. Alemayehu N. and Becker H., 2002. Genotypic diversity and patterns of variation in a germplasm material of Ethiopian mustard (Brassica carinataA.).Genetic Resources and Crop Evolution, 49(6): 573-582.

[27]. Mekonnen T., Wakjira A. and Genet T., 2014. Correlation and Path Coefficient Analysis among Yield Component Traits of Ethiopian Mustard (Brassica carinata A.) at Adet, Northwestern, Ethiopia Journal of Plant Science, 2(2): 89-96.

[28]. Chahal, G.S. and S.S. Gosal, 2002. Principles and Procedures of Plant Breeding: Biotechnology and Conventional Approaches. Alpha Science International, United Kingdom, ISBN: 9781842650363, Pages: 604.

[29]. Saleem, N., Jan, S., Atif, M., Khurshid, H., Khan, S., Abdullah, M., Jahanzaib, M., Ahmed, H., Ullah, S., Iqbal, A. and Naqi, S., 2017. Multivariate Based Variability within Diverse Indian Mustard (Brassica juncea L.) Genotypes. Open Journal of Genetics, 7(02): 69.

[30]. Bozokalfa M., Eşiyok D. And Aşçioğul T., 2016. Diversity Pattern among Agromorphological Traits of the Swiss chard (Beta Vulgaris L.) Genetic Resources of Turkey. Turkish Journal of Agriculture and Forestry, 40(5): 684-695. 